\title{
Introduction: Intelligent Learning Assessment in Serious Games
}

\author{
Riccardo Berta ${ }^{1}$, Pablo Moreno-Ger² \\ 1First and corresponding Author University of Genoa, riccardo.berta@unige.it \\ ${ }^{2}$ Universidad Internacional de La Rioja, pablo.moreno@unir.net
}

\begin{abstract}
There is a consensus that Serious Games (SGs) have a potential as a tool for education, and the conversation is no longer about whether it makes sense to use SGs in education, but how to exploit their potential to become a revolution is to become effective in the evaluation of the learning progress of the player. The aim of this special issue is to presents some recent in the field of assessment of learning.
\end{abstract}

Keywords: Assessment

Serious Games (SGs) are computer games designed in order to have an impact on the target user, which is beyond the pure entertainment aspect [1]. In the educational field, a SG is thus designed both to be appealing, like commercial games, and to meet specific educational goals as well. In order to support the latter requirement, SGs are evolving and specifically contemplating educational features including technology-assisted modules for the assessment of student performance [2].

Past literature has explored how technology can improve the quality of assessments in general, also replacing certain tasks previously done by instructors [3]. Specifically, as players progress through a SG, they accumulate points/coins/bonus/etc., which in turn enable higher difficult tasks in the next levels. Incorporating this information in the assessment module can push SG beyond traditional (and limited) approaches to assessment such as questionnaires, that usually interrupt rather than facilitate the learning process [4]. Designing this form of "in-game" assessment is a challenging and time-consuming activity. However, it has to be the distinctive feature of any SG, where game mechanics (e.g., score, points, bonus, levels, leader-boards, etc.) should be consistent with the pedagogical target [5].

In this context, the assessment of learning in SGs can be defined as the process of reporting results about the effectiveness of the educational activity (in terms of the progress towards the established learning outcomes) provided during the game play, exploiting information coming from the interaction of the player with the game [6]. Data gathered during the game play, like game analytics (game events, player actions, etc.) [7] and information gathered from innovative controllers (user movements, physiological measurements, etc.) have the potential to automate (through algorithms, AI statistical methods, etc.) the assessment process and to improve the adoption of SGs by stakeholders (industry training responsible, teachers, schools, etc.) by proving the evidence of SG's impact on learning [8].

However, caution is required: assessing user performance regarding an educational goal within the simulated virtual-world of a game is not a trivial matter. The integration of assessment in games will require the definition of a methodology for selecting the data to be gathered, the right algorithms to manipulate the data and new approaches to providing feedback to the user. This methodology has to be general and modular, in order to be seamlessly applicable in different games.

This special issue on "Intelligent Learning Assessment in Serious Games" of the International Journal on Serious Games has three main contributions focused on tackling this problem, which we identify as a key requirement for the future of the SGs industry.

In "Set-theoretical and Combinatorial Instruments for Problem Space Analysis in Adaptive Serious Games" by Enkhbold Nyamsuren, Han L.J. van der Maas and Matthias Maurer [9], a methodology and some instruments are proposed for analyzing Computerized Adaptive Practice (CAP) system used for assessing player's expertise and difficulties of in-game problems. The contribution demonstrates the viability of the proposed approach in two case studies.

In the second paper, entitled "Data Analytics of Mobile Serious Games: Applying Bayesian Data Analysis Methods" by Heide Lukosch and Scott Cunningham [10], a mobile game for teaching 
resuscitation is presented. The game applies Bayesian methods for analyzing large dataset coming from a field test in three schools with 171 real players.

Finally, the article "Gamified In-Home Rehabilitation for Stroke Survivors: Analytical Review" by Paul Tamayo-Serrano, Samir Garbaya and Pierre Blazevic [11], presents a review of gamified stroke rehabilitation systems in order to identify the most important features.

All three articles represent prime examples of how intelligent assessment features can significantly enhance the educational value and practical applicability of serious games.

\section{References}

[1] Greitzer, F.L., Kuchar, O. A., and Huston, K. , "Cognitive science implications for enhancing training effectiveness in a serious gaming context," ACM Journal on Educational Resources in Computing, vol. 7, no. 3, article 2, 2007. https://doi.org/10.1145/1281320.1281322

[2] Bellotti, F., Kapralos, B., Lee, K., Moreno-Ger, P., Berta, R. “Assessment in and of serious games: An overview”, in Advances in Human-Computer Interaction, art. no. 136864, 2013 https://doi.org/10.1155/2013/136864

[3] N. Zoanetti, "Software for online testing and quizzes", http://www.assessmentfocus.com/online-testing.php, accessed online on March 2018

[4] Bente, G., and Breuer, J., "Making the implicit explicit: embedded measurement in serious games," in Serious Games: Mechanisms and Effects, U. Ritterfeld, M. J. Cody, and P. Vorderer, Eds., pp. 322-343, Routledge, New York, NY, USA, 2009.

[5] Bellotti, F., Kapralos, B., Lee, K., Moreno-Ger, P., Berta, R. "Assessment in and of serious games: An overview", in Advances in Human-Computer Interaction, art. no. 136864,2013 https://doi.org/10.1155/2013/136864

[6] Hauge, J.B., Boyle, E., Mayer, I., Nadolski, R., Riedel, J.C.K.H., Moreno-Ger, P., Bellotti, F., Lim, T., Ritchie, J. "Study design and data gathering guide for serious games' evaluation" in Gamification: Concepts, Methodologies, Tools, and Applications, 1-4, pp. 425-451, 2015 https://doi.org/10.4018/978-1-4666-4773-2.ch018

[7] Ninaus, M., Kober, S.E., Friedrich, E.V.C., Dunwell, I., De Freitas, S., Arnab, S., Ott, M., Kravcik, M., Lim, T., Louchart, S., Bellotti, F., Hannemann, A., Thin, A.G., Berta, R., Wood, G., Neuper, C. "Neurophysiological methods for monitoring brain activity in serious games and virtual environments: A review" in International Journal of Technology Enhanced Learning, 6 (1), pp. 78-103, 2014 https://doi.org/10.1504/IJTEL.2014.060022

[8] Hauge, J.B., Berta, R., Fiucci, G., Manjon, B.F., Padron-Napoles, C., Westera, W., Nadolski, R. "Implications of learning analytics for serious game design" in Proceedings of the IEEE 14th International Conference on Advanced Learning Technologies, ICALT 2014, art. no. 6901445, pp. 230-232, 2014 https://doi.org/10.1109/ICALT.2014.73

[9] Nyamsuren, E., van der Maas, H., Maurer, M., "Set-theoretical and Combinatorial Instruments for Problem Space Analysis in Adaptive Serious Games" in The Int.1 Journal of Serious Games, Vol. 5, Nr. 1, Mar. 2018 https://doi.org/10.17083/ijsg.v5i1.219

[10] Lukosch, H., Cunningham, S., "Data Analytics of Mobile Serious Games: Applying Bayesian Data Analysis Methods" in The Int.l Journal of Serious Games, Vol. 5, Nr. 1, Mar. 2018 https://doi.org/10.17083/ijsg.v5i1.222

[11] Tamayo-Serrano, P., Garbaya, A., Blazevic, P., "Gamified In-Home Rehabilitation for Stroke Survivors: Analytical Review” in The Int.l Journal of Serious Games, Vol. 5, Nr. 1, Mar. 2018 https://doi.org/10.17083/ijsg.v5i1.224 